\title{
Bifurcation and Chaos Analysis of the Spur Gear Transmission System for One-Way Clutch, Two-Shaft Assembly
}

\author{
Zhihui Liu, ${ }^{1,2,3}$ Hongzhi Yan, ${ }^{1,3}$ Yuming Cao, ${ }^{1,3}$ and Yuqing Lai $^{2}$ \\ ${ }^{1}$ The State Key Laboratory of High-Performance and Complex Manufacturing, Central South University, Changsha 410083, China \\ ${ }^{2}$ Department of Mechanical and Energy Engineering, Shaoyang University, Shaoyang 422000, China \\ ${ }^{3}$ School of Mechanical and Electrical Engineering, Central South University, Changsha 410083, China
}

Correspondence should be addressed to Hongzhi Yan; yhzcsu@163.com

Received 19 March 2017; Accepted 15 June 2017; Published 20 August 2017

Academic Editor: Francesco Braghin

Copyright (C) 2017 Zhihui Liu et al. This is an open access article distributed under the Creative Commons Attribution License, which permits unrestricted use, distribution, and reproduction in any medium, provided the original work is properly cited.

\begin{abstract}
A four-degree-of-freedom nonlinear transverse and torsional vibration model of spur gear transmission system for one-way clutch, two-shaft assembly was developed, in which the one-way clutch was modeled as a piecewise nonlinear spring with discontinuous stiffness, considering the factors such as the time-varying gear mesh stiffness, static transmission error, and nonlinearity backlash. With the help of bifurcation diagrams, time domain response diagrams, phase plane diagrams, and Poincaré maps, the effects of the excitation frequency and the torsional stiffness of one-way clutch on the dynamic behavior of gear transmission system for one-way clutch, two-shaft assembly are investigated in detail by using Runge-Kutta method. Numerical results reveal that the system response involves period-1 motion, multiperiodic motion, bifurcation, and chaotic motion. Large torsional stiffness of one-way clutch can increase the impact and lead to instability in the system. The results can present a useful source of reference for technicians and engineers for dynamic design and vibration control of such system.
\end{abstract}

\section{Introduction}

The one-way clutch, two-shaft assembly is the key component of the two-speed transmission, which is widely used in loaders, helicopters, tanks, military trucks, and other gear transmission systems. The two-speed transmission is generally composed of the outer ring gear, intermediate input shaft, inner star wheel, and a plurality of cylinder rollers or sprags. The one-way clutch is made up of the outer ring gear, sprags, and the inner star wheel. The outer ring gear and the inner star wheel can be engaged or disengaged according to their relative angular speed, which can lead to the two-speed transmission having two kinds of output speed.

It is well known that gear mechanisms are widely used owing to their rather large technical advantages. However, they are known as one of the most important sources of vibration and noise in mechanical transmission systems. The vibration, noise, and wear performances are mainly affected by the gear pair dynamic characteristics.

There is a growing literature on nonlinear dynamics of gear pairs in the past decades. And to analyze the nonlinear dynamic behaviors of gear transmission system, the different excitation of static transmission error, dynamic meshing stiffness, bearing contact stiffness, prime mover, clearance nonlinearity, and load fluctuation are added [17]. Walha et al. [8] investigated the dynamics of a twostage gear system with mesh stiffness and backlash. Parker et al. [9] used a finite element/contact mechanic model to investigate the dynamic response of a spur gear pair. And the dynamic characteristics of a gear pair are analyzed across a wide range of frequency and torques. Al-Shyyab and Kahraman [10] adopted lumped parameter method to establish a nonlinear time-varying dynamic model for multimesh gear, considering the nonlinear gear gap and gear meshing stiffness. The multiterm harmonic balance method (HBM) was used to gain the steady-state period-1 response, including the Root Mean Square (RMS) and the mean value of the vibration amplitude across a wide range of frequency, taking into account different gear meshing stiffness. He et al. [4] analyzed the dynamic characteristics of a spur gear pair, considering the dynamic meshing stiffness and sliding friction. The influence of friction on dynamic transmission 
error is discussed. In recent years, many scholars have studied the bifurcation and chaos characteristics of gear transmission system [11]. Wang et al. [12] made use of the bifurcation diagrams, phase plane diagrams, Poincaré maps, time domain response diagrams, and amplitude-frequency spectrums to investigate the effects of the pinion speed and stiffness on the dynamic behavior of gear transmission system for locomotive. Xiang et al. [13] built a six-degree-of-freedom nonlinear dynamic model of a spur gear-bearing system with time-varying stiffness, gear backlash, and surface friction. In [13], bifurcation diagrams of the mesh stiffness and the rotational speed ratio as control parameters were used to observe the dynamic orbits of the system. The chaotic motion was identified from the largest Lyapunov exponents, Poincaré maps, and the phase diagrams of the system. Chang-Jian and Chang [14] studied the dynamic orbits of a singledegree-of-freedom spur gear system by using bifurcation diagrams with the dimensionless damping coefficient and the dimensionless rotational speed ratio as control parameters. Gou et al. [15] used the simple cell mapping method and escape time algorithm to examine the bifurcation dynamic characteristics of the multiparameter coupling in torsionvibration gear system. Although most scholars study the steady-state response analysis of gear transmission system, Khabou et al. [16] studied a spur gear dynamic behavior in the transient regime.

The dynamic analysis of one-way clutch, two-shaft assembly is to study the coupling nonlinear characteristics of oneway clutch and gear transmission system. Though application of one-way clutch, two-shaft assembly is extensive, literature on its dynamics is limited. In the aspects of dynamic characteristics study of one-way clutch, Vernay et al. [17] pointed out and quantified the possible relative sliding effects between sprag-type races of one-way clutches by experiments. GillJeong [18] verified the nonlinear behavior analysis of a paired spur gear system with a one-way clutch for the first time. He found that the dynamic transmission error of a gear system with a one-way clutch was reduced over the entire frequency range compared to a pure gear system with three-degreeof-freedom torsional vibration model. However, the effects of parameters such as bearing stiffness, bearing backlash, torsion stiffness, and damping of clutch on the nonlinear behavior of gear system coupled with a one-way clutch were not considered. In order to investigate the effect of the one-way clutch on the dynamic performance of the coupling transmission, a great deal of research effort has been devoted to the study of the nonlinear dynamics of one-way clutches in belt-pulley systems. In such system, the one-way clutch is usually modeled as a two-degree-offreedom model, which is regarded as piecewise linear [19]. Zhu and Parker [20] used a two-degree-of-freedom model to examine the nonlinear dynamics of a two-pulley belt system with a one-way clutch through three methods of multiterm harmonic balance, numerical integration, and the bifurcation software AUTO separately. Zhu and Parker [21] also used the method of multiple scales to obtain the periodic solutions of a two-pulley belt system with clearance-type nonlinearity. The stable steady-state periodic responses of a belt-drive system with a one-way clutch were studied comprehensively [22-25].
Ding and $\mathrm{Zu}$ [22] studied the effects of the system parameters on the nonlinear steady-state response of a belt-drive system with a one-way clutch and had a conclusion that one-way clutch not only decreases the resonance amplitude of the driven pulley and shaft's rotational vibration but also reduces the resonance region of the belt's transverse vibration. Ding [23] also presented the stable steady-state periodic response of a two-pulley belt-drive system coupled with one-way clutch under double excitation for the first time. The Galerkin method was adapted to exam whether the one-way device can efficiently reduce the rotation vibration and transverse vibration of the pulley belt dynamic system either.

In view of the lack of research for dynamic analysis for one-way clutch, two-shaft assembly, the present paper concentrates on building and analyzing a mathematical model for such system. For the first time, a four-degree-offreedom nonlinear transverse and torsional vibration model of spur gear transmission system for one-way clutch, twoshaft assembly was modeled, considering the gear masses $m_{1}$ and $m_{2}$, a nonlinear mesh stiffness $k_{h}(t)$, and mesh damping $c_{h}$. The one-way clutch is modeled as a piecewise nonlinear spring with discontinuous stiffness that separates the driven gear into two degrees of freedom. The main purpose is to inspect the influences of the gear speed and the torsional stiffness of one-way clutch on the system dynamic behavior and find out some useful reference information for technicians and engineers to dynamic design and vibration control of such system.

\section{Working Principle of One-Way Clutch, Two-Shaft Assembly}

Figure 1 shows the structural schematic of one-way clutch, two-shaft assembly, which is composed primarily of bearing $(1,2)$, gear $(1,2)$, sprags, input shaft, output shaft, and inner ring. Gear 1 is fixed on the input shaft by the method of spline interference fit. Gear 2, sprags, and the inner ring, which is connected to the output shaft through key connection, are formed into a one-way clutch. Figure 2 is used as a reference to explain the work principle of the one-way clutch. When the one-way clutch is not working, the tension of the spring ensures that the sprags keep in touch with gear 2 and the inner ring. When gear 2 begins to rotate clockwise under the action of gear 1 or the rotation speed of gear 2 exceeds the rotation speed of the inner ring, the sprag will rotate around its center in clockwise direction with the spring tension and the tangential friction at the contact point. With the sprag rotating, the distance of the two contact points between the sprag and gear 2 and the inner ring would become longer, and the power can be transmitted from gear 2 to the inner ring. As gear 2 and the inner ring are fully wedged by the sprags, the rotation speed of gear 2 and the inner ring will be the same. Conversely, gear 2 will be overrunning and the power could not be transmitted to the inner ring when gear 2 rotates anticlockwise or the rotation speed of gear 2 is slower than the rotation speed of the inner ring. So it can be concluded that the rotation direction of gear 1 determines whether the load can be transferred for the one-way clutch, two-shaft assembly. 


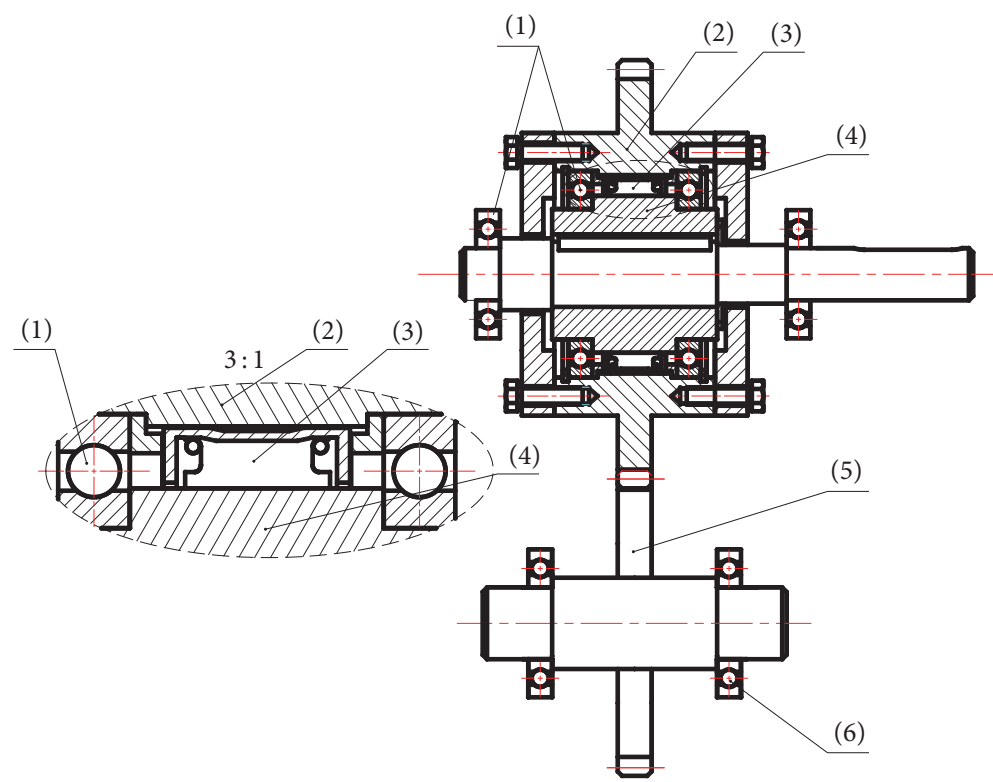
(1) Bearing 2
(4) Inner ring
(2) Gear 2
(5) Gear 1
(3) Sprag
(6) Bearing 1

FIGURE 1: Structural diagram of one-way clutch, two-shaft assembly.

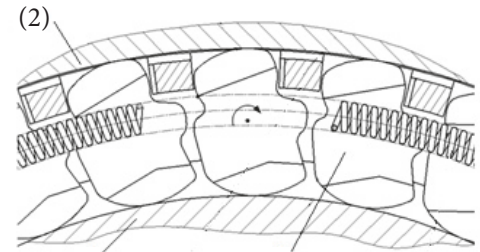

(4)

(3)
(2) Gear 2
(3) Sprag
(4) Inner ring

FIgURE 2: Structural schematic of one-way clutch.

\section{Mathematical Model}

Figure 3 shows a schematic illustration of the dynamic model of one-way clutch, two-shaft assembly considered in the present analysis. In this model, $r_{1}$ is the base circle radius of gear $1, r_{2}$ is the base circle radius of gear $2, I_{1}$ is the mass moments of inertia of gear $1, I_{2}$ is the mass moments of inertia of gear 2, $I_{o}$ is the mass moment of inertia of inner ring, $m_{1}$ is the mass of gear $1, m_{2}$ is the mass of gear 2, $c_{h}$ is the damping coefficient of the gear mesh, $k_{h}(t)$ is the time-varying stiffness coefficient of the gear mesh, which can be obtained by assuming a rectangular wave as shown in $(2)[8,18]$, where $k_{h}$ is the average mesh stiffness value, $k_{h r}$ and $\phi_{r}$ are the $r$ th Fourier coefficient and phase angle of $k_{h}(t)$, respectively, and $k_{h} / k_{t p}=\varepsilon_{r}, k_{h r} / k_{t p}=\sqrt{2-2 \cos \left(2 \pi r\left(\varepsilon_{r}-1\right)\right)} /(\pi r), \phi_{r}=$ $a \tan \left(\left(1-\cos \left(2 \pi r\left(\varepsilon_{r}-1\right)\right)\right) /\left(\sin \left(2 \pi r\left(\varepsilon_{r}-1\right)\right)\right)\right), \varepsilon_{r}$ is the involute contact ratio, $R=5, f_{h}$ is the force-displacement on the mesh line function of gear mesh, $c_{1}$ is the damping coefficient of bearing $1, c_{2}$ is the damping coefficient of bearing $2, k_{i}, f_{i}$ are the contact stiffness coefficient and the force-transverse displacement function of $i$ th bearing $(i=1,2), K_{c}$ is the torsional stiffness coefficient of one-way clutch, and $C_{c}$ is the torsional damping coefficient of one-way clutch. From the lumped parameter mass method and Newton's laws of motion, the five-degree-of-freedom nonlinear model of the geared clutch bearing system dynamic model can show that

$$
\begin{aligned}
& m_{1} y_{1}^{\prime \prime}+c_{1} y_{1}^{\prime}+c_{h}\left(\left(r_{1} \theta_{1}-r_{2} \theta_{2}\right)^{\prime}+y_{1}^{\prime}-y_{2}^{\prime}-e^{\prime}\right) \\
& \quad+k_{1} f_{1}\left(y_{1}\right) \\
& \quad+k_{h}(t) f_{h}\left(r_{1} \theta_{1}-r_{2} \theta_{2}+y_{1}-y_{2}-e\right)=-F_{1}, \\
& m_{2} y_{2}^{\prime \prime}+c_{2} y_{2}^{\prime}-c_{h}\left(\left(r_{1} \theta_{1}-r_{2} \theta_{2}\right)^{\prime}+y_{1}^{\prime}-y_{2}^{\prime}-e^{\prime}\right)
\end{aligned}
$$




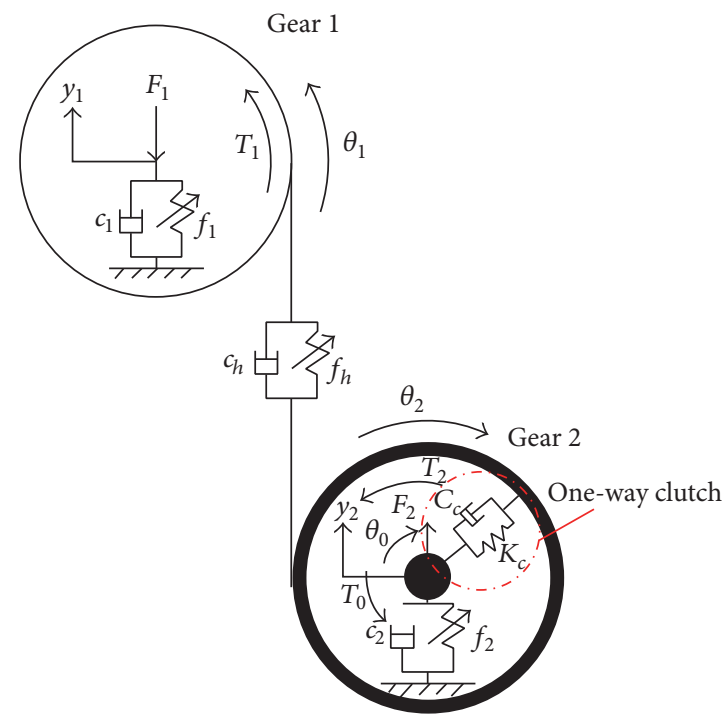

FIGURE 3: Schematic diagram of one-way clutch, two-shaft assemblies.

$$
\begin{aligned}
& \quad+k_{2} f_{2}\left(y_{2}\right) \\
& \quad-k_{h}(t) f_{h}\left(r_{1} \theta_{1}-r_{2} \theta_{2}+y_{1}-y_{2}-e\right)=F_{2}, \\
& I_{1} \theta_{1}^{\prime \prime}+c_{h}\left(\left(r_{1} \theta_{1}-r_{2} \theta_{2}\right)^{\prime}+y_{1}^{\prime}-y_{2}^{\prime}-e^{\prime}\right) \cdot r_{1} \\
& \quad+k_{h}(t) f_{h}\left(r_{1} \theta_{1}-r_{2} \theta_{2}+y_{1}-y_{2}-e\right) \cdot r_{1}=T_{1}(t), \\
& I_{2} \theta_{2}^{\prime \prime}-c_{h}\left(\left(r_{1} \theta_{1}-r_{2} \theta_{2}\right)^{\prime}+y_{1}^{\prime}-y_{2}^{\prime}-e^{\prime}\right) \cdot r_{2} \\
& \quad-k_{h}(t) f_{h}\left(r_{1} \theta_{1}-r_{2} \theta_{2}+y_{1}-y_{2}-e\right) \cdot r_{2}=-T_{2}(t), \\
& I_{o} \theta_{o}^{\prime \prime}=T_{2}(t)-T_{o},
\end{aligned}
$$

where gear 1 and gear 2 are assumed perfect involute spur gears with no modifications and the torsional and transverse flexibility of the input shaft and output shaft are neglected. Here, $y_{i}$ and $\theta_{i}$ are the transverse and torsional displacements of the $i$ th gear $(i=1,2), \theta_{o}$ is the torsional displacement of the inner ring, and ()$^{\prime}$ means derivative with respect to time $t$. The input torque $T_{1}(t)$ is assumed to be fluctuating as $T_{1}(t)=T_{1 m}+T_{1 a T}(t)$, where $T_{1 m}$ is the average torque and $T_{1 a T}(t)$ is the fluctuating torque, considered as $T_{1 a T}(t)=$ $T_{1 a T} \sin \left(\omega_{a} t+\phi_{T}\right)$. Forcing term $T_{2}(t)$, which is connected with the piecewise nonlinear force-displacement function $f_{c}(x)$ shown in (4), and force-velocity function $f_{c}^{\prime}(x)$ [26], is the torque transferred from gear 2 to the inner ring, as shown in (3). And the output torque $T_{o}(t)$ applied on the inner ring or output shaft is assumed to be constant: that is, $T_{o}(t)=T_{o m}$. The external radial forces $F_{1}$ and $F_{2}$ are preloads which are applied to both rolling element bearings. The static transmission error $e(t)$, connected with the manufacturing and assembling of the gears, is considered sinusoidal excitation as $e(t)=\tilde{e} \sin \left(\omega_{e} t+\phi_{h}\right)$

$$
k_{h}(t)=k_{h}\left(t+\frac{2 \pi}{\omega}\right)=k_{h}+\sum_{r=1}^{R} k_{h r} \cos \left(r \omega t-\phi_{r}\right),
$$

$$
\begin{aligned}
& T_{2}(t)= K_{c} f_{c}\left(\theta_{2}-\theta_{o}\right)^{3 / 2} \\
&+C_{c} f_{c}^{\prime}\left(\theta_{2}-\theta_{o}\right) f_{c}\left(\theta_{2}-\theta_{o}\right)^{1 / 4}, \\
& f_{c}(x)= \begin{cases}x & x>0, \\
0 & x \leq 0 .\end{cases}
\end{aligned}
$$

It is assumed that $r_{1} \theta_{1}=y_{g 1}, r_{2} \theta_{2}=y_{g 2}$, and $r_{2} \theta_{o}=$ $y_{c o}$, where the parameters of $y_{g 1}, y_{g 2}$, and $y_{c o}$ are defined as the displacement on the direction of mesh line of gear 1 , gear 2 and the inner ring, respectively. Through defining new variables $q(t)$ and $q_{o}(t)$ as $q(t)=y_{g 1}-y_{g 2}+y_{1}-y_{2}-e(t)$ and $q_{o}(t)=y_{g 2}-y_{c o}$, (1) can be simplified further as

$$
\begin{aligned}
& m_{1} y_{1}^{\prime \prime}+c_{1} y_{1}^{\prime}+c_{h} q^{\prime}+k_{1} f_{1}\left(y_{1}\right)+k_{h}(t) f_{h}(q)=-F_{1}, \\
& m_{2} y_{2}^{\prime \prime}+c_{2} y_{2}^{\prime}-c_{h} q^{\prime}+k_{2} f_{2}\left(y_{2}\right)-k_{h}(t) f_{h}(q)=F_{2}, \\
& m_{c} q^{\prime \prime}-m_{c} y_{1}^{\prime \prime}+m_{c} y_{2}^{\prime \prime}+c_{h} q^{\prime}+k_{h}(t) f_{h}(q) \\
& =m_{c}\left(\frac{F_{1}(t) r_{1}^{2}}{I_{1}}+\frac{F_{2}(t) r_{2}^{2}}{I_{2}}\right)-m_{c} e^{\prime \prime}(t), \\
& q_{o}^{\prime \prime}-\frac{c_{h} r_{2}^{2}}{I_{2}} q^{\prime}-\frac{k_{h}(t) r_{2}^{2}}{I_{2}} f_{h}(q) \\
& =-F_{2}(t) r_{2}^{2}\left(\frac{1}{I_{2}}+\frac{1}{I_{o}}\right)+\frac{F_{o} r_{2}^{2}}{I_{o}} .
\end{aligned}
$$

Here, $m_{c}$ is the equivalent gear pair mass. The piecewise linear displacement functions $f_{i}\left(y_{i}\right)$ and $f_{h}(q)$ include the half of backlash of bearings $b_{i}(i=1,2)$ and the half of 
backlash of the gears $b_{h}$, which can be expressed as (7) and (8).

$$
\begin{aligned}
m_{c} & =\frac{1}{\left(r_{1}{ }^{2} / I_{1}+r_{2}{ }^{2} / I_{2}\right)}, \\
f_{i}\left(y_{i}\right) & =\left\{\begin{array}{ll}
y_{i}-b_{i} & y_{i}>b_{i} \\
0 & \left|y_{i}\right| \leq b_{i} \\
y_{i}+b_{i} & y_{i}<-b_{i}
\end{array} \quad(i=1,2),\right. \\
f_{h}(q) & = \begin{cases}q-b_{h} & q>b_{h} \\
0 & |q| \leq b_{h} \\
q+b_{h} & q<-b_{h} .\end{cases}
\end{aligned}
$$

A dimensionless form of (5) can be obtained by letting

$$
\begin{aligned}
z_{i}(t) & =\frac{y_{i}(t)}{b_{c}}, \\
\gamma_{1}(t) & =\frac{q(t)}{b_{c}}, \\
\gamma_{2}(t) & =\frac{q_{o}(t)}{b_{c}}, \\
\omega_{i} & =\sqrt{\frac{k_{i}}{m_{i}}}, \quad(i=1,2), \\
\omega_{n} & =\sqrt{\frac{k_{h}}{m_{c}}}, \\
k_{i 3} & =\frac{m_{c}}{m_{i}}+\omega_{n} t, \frac{k_{h r}}{m_{i} \omega_{n}^{2}} \cos \left(r \omega_{h} \tau-\phi_{r}\right) \\
k_{i i} & =\frac{\omega_{i}^{2}}{\omega_{n}^{2}}, \quad(i=1,2), \\
\xi_{33} & =\frac{c_{h}}{2 m_{c} \omega_{n}}, \\
\xi_{T 3} & =\frac{\omega_{a}}{\omega_{n}}, \quad(i=1,2), \\
\xi_{i i} & =\frac{c_{i}}{2 m_{i} \omega_{n}}, \\
\xi_{n} &
\end{aligned}
$$

TABLE 1: Properties of one-way clutch, two-shaft assembly.

\begin{tabular}{lcc}
\hline Item & Notation & Value \\
\hline Gears & & \\
Involute contact ratio & $\varepsilon_{r}$ & 1.5 \\
Radius of gears & $r_{1}, r_{2}$ & $0.04 \mathrm{~m}$ \\
Rotational inertia of gears & $I_{1}, I_{2}$ & $0.0008 \mathrm{~kg} \cdot \mathrm{m}^{2}$ \\
Mesh stiffness & $k_{h}$ & $2 \times 10^{8} \mathrm{~N} / \mathrm{m}$ \\
Gear mesh damping & $c_{h}$ & 707 \\
Bearing contact damping & $c_{1}, c_{2}$ & 566 \\
Quality of gears & $m_{1}, m_{2}$ & $1 \mathrm{~kg}$ \\
One-way clutch & & \\
Rotational inertia of clutch & $I_{o}$ & $0.0008 \mathrm{~kg} \cdot \mathrm{m}^{2}$ \\
Torsional stiffness & $K_{c}=K_{c o}$ & $2467 \mathrm{~N} \cdot \mathrm{m} / \mathrm{rad}$ \\
Torsional damping & $C_{c}$ & 0.217 \\
\hline
\end{tabular}

$$
\begin{aligned}
& k_{33}=1+\sum_{r=1}^{5} \frac{k_{h r}}{m_{c} \omega_{n}{ }^{2}} \cos \left(r \omega_{h} \tau-\phi_{r}\right), \\
& k_{43}=\frac{k_{h} r_{2}{ }^{2}}{I_{2} \omega_{n}{ }^{2}}+\sum_{r=1}^{5} \frac{k_{h r} r_{2}{ }^{2}}{I_{2} \omega_{n}{ }^{2}} \cos \left(r \omega_{h} \tau-\phi_{r}\right),
\end{aligned}
$$

where $b_{c}$ is the characteristic length and the terms $\omega_{a}$ and $\omega_{e}$ are the fundamental excitation frequencies of external torque fluctuations and the internal static transmission error, respectively. And the dimensionless governing equations of motion are shown as (10), where $z_{i}$ is the dimensionless transverse displacement of the $i$ th gear $(i=1,2), \gamma_{1}$ is dimensionless difference between the dynamic transmission error and the static transmission error of the two gears, and $\gamma_{2}$ is the dimensionless dynamic transmission error between gear 2 and the inner ring.

\section{Parametric Studies on Characteristics of Bifurcation and Chaos}

In this section, a case study is analyzed to demonstrate the effect of the rotation speed of gear 2 and the torsional stiffness of one-way clutch on its dynamic characteristics.

For the structure of one-way clutch, two-shaft assemblies, gear 2 and the inner ring can be coupled or decoupled as the one-way clutch is active.

The main parameters of the one-way clutch, two-shaft assemblies are listed in Table 1. Equation (10) describes a strongly nonlinear dynamic system with time-varying gear mesh stiffness, nonlinear backlash, and nonlinear forcedisplacement function of one-way clutch. And it is solved by using the fourth-order Runge-Kutta method. In order to obtain a better understanding of the dynamic behavior of the one-way clutch, two-shaft assembly, the time series data were used to generate the bifurcation diagram, phase diagram, and Poincaré maps. The periodic responses are shown by varying the excitation frequency and the torsional 
stiffness of one-way clutch. On the other hand, since the new introduced coordinates $z_{1}$ and $z_{2}$ have the similar nonlinear behavior, the dynamic response of the transverse vibration $z_{2}$ of gear 2 is selected to analyze the bifurcation and chaos characteristics. In order to find out the dynamic response of the windup angle of one-way clutch, the character of dynamic transmission error between gear 2 and the inner ring is chosen to be analyzed. Furthermore, in order to avoid the risk of obtaining transient solutions and minimize computing, the initial conditions of $z_{2}, z_{2}^{\prime}, \gamma_{1}, \gamma_{1}^{\prime}, \gamma_{2}$, and $\gamma_{2}^{\prime}$ are all set to be zero.

$$
\begin{aligned}
& {\left[\begin{array}{cccc}
1 & 0 & 0 & 0 \\
0 & 1 & 0 & 0 \\
-1 & 1 & 1 & 0 \\
0 & 0 & 0 & 1
\end{array}\right]\left[\begin{array}{l}
z_{1}^{\prime \prime}(\tau) \\
z_{2}^{\prime \prime}(\tau) \\
\gamma_{1}^{\prime \prime}(\tau) \\
\gamma_{2}^{\prime \prime}(\tau)
\end{array}\right]} \\
& +2\left[\begin{array}{cccc}
\xi_{11} & 0 & \xi_{13} & 0 \\
0 & \xi_{22} & -\xi_{23} & 0 \\
0 & 0 & \xi_{33} & 0 \\
0 & 0 & -\xi_{43} & 0
\end{array}\right]\left[\begin{array}{l}
z_{1}^{\prime}(\tau) \\
z_{2}^{\prime}(\tau) \\
\gamma_{1}^{\prime}(\tau) \\
\gamma_{2}^{\prime}(\tau)
\end{array}\right] \\
& +\left[\begin{array}{cccc}
k_{11} & 0 & k_{13} & 0 \\
0 & k_{22} & -k_{23} & 0 \\
0 & 0 & k_{33} & 0 \\
0 & 0 & -k_{43} & 0
\end{array}\right]\left[\begin{array}{c}
f_{1}\left(z_{1}(\tau)\right) \\
f_{2}\left(z_{2}(\tau)\right) \\
f_{h}\left(\gamma_{1}(\tau)\right) \\
0
\end{array}\right]=\{F(\tau)\} \text {, } \\
& \{F(\tau)\}=\left[\begin{array}{c}
-\widehat{F}_{1} \\
\widehat{F}_{2} \\
\frac{m_{c} r_{1}^{2}}{I_{1}} \widehat{F}_{1 m}+\frac{m_{c} r_{2}^{2}}{I_{2}} \widehat{F}_{21} \\
-\widehat{F}_{22} r_{2}^{2}\left(\frac{1}{I_{2}}+\frac{1}{I_{o}}\right)+\frac{\widehat{F}_{o} r_{2}{ }^{2}}{I_{o}}
\end{array}\right] \\
& +\left[\begin{array}{c}
0 \\
0 \\
F_{a h} \omega_{h}^{2} \\
0
\end{array}\right] \sin \left(\omega_{h} \tau+\phi_{h}\right) \\
& +\left[\begin{array}{c}
0 \\
0 \\
\frac{m_{c} r_{1}^{2}}{I_{1}} \widehat{F}_{1 a T} \\
0
\end{array}\right] \sin \left(\omega_{T} \tau+\phi_{T}\right) \\
& \widehat{F}_{i}=\frac{F_{i}}{\left(m_{i} b_{c} \omega_{n}^{2}\right)}, \quad i=1,2 \text {, } \\
& \widehat{F}_{1 m}=\frac{F_{1 m}}{\left(m_{c} b_{c} \omega_{n}^{2}\right)},
\end{aligned}
$$

$$
\begin{aligned}
& F_{a h}=\frac{\tilde{e}}{b_{c}}, \\
& \widehat{F}_{1 a T}=\frac{F_{1 a T}}{\left(m_{c} b_{c} \omega_{n}^{2}\right)}, \\
& \widehat{F}_{o}=\frac{F_{o}}{\left(b_{c} \omega_{n}{ }^{2}\right)}, \\
& \widehat{F}_{21}=\frac{K_{c} f_{c}\left(\gamma_{2}\right)^{3 / 2} b_{c}^{3 / 2}}{r_{2}{ }^{5 / 2} m_{c} b_{c} \omega_{n}^{2}}+\frac{C_{c} f_{c}^{\prime}\left(\gamma_{2}\right) f_{c}\left(\gamma_{2}\right)^{1 / 4} b_{c}^{5 / 4}}{r_{2}{ }^{9 / 4} m_{c} b_{c} \omega_{n}}, \\
& \widehat{F}_{22}=\frac{K_{c} f_{c}\left(\gamma_{2}\right)^{3 / 2} b_{c}^{3 / 2}}{r_{2}{ }^{5 / 2} b_{c} \omega_{n}{ }^{2}}+\frac{C_{c} f_{c}^{\prime}\left(\gamma_{2}\right) f_{c}\left(\gamma_{2}\right)^{1 / 4} b_{c}^{5 / 4}}{r_{2}{ }^{9 / 4} b_{c} \omega_{n}} .
\end{aligned}
$$

4.1. Effect of Excitation Frequency. The ratio of the bearing stiffness to average gear mesh stiffness $\widehat{k}$ is introduced to represent the change of support stiffness. The frequency parameter $\omega_{h}$ is assigned as control parameters. The bifurcation diagram of the dimensionless transverse displacement of gear 2 with excitation frequency $\omega_{h}$ change is presented in Figure 4.

It is well known that the jump phenomenon usually exists in the dynamic response of nonlinear system. It could be seen clearly in Figure 4 that there is a phenomenon of jumping at value of $\omega_{h}=0.61$. The one-way clutch, two-shaft assemblies system mainly exhibits period-one motion at low values or at high excitation frequency: that is, $\omega_{h}<0.69$ or $\omega_{h}>1$.66. Just as shown in Figure 5(a), the time domain response diagram is a sine wave, the phase plane diagram is only one closed circle, and the Poincaré map is a single point. It is observed that the system goes into chaotic region within the range of $0.7 \leq \omega_{h} \leq 0.87,0.94 \leq \omega_{h} \leq 1.13$, and $1.3 \leq \omega_{h} \leq$ 1.59. It can be seen in Figure 5(b) that the time domain response diagram shows a nonperiodic motion, the phase plane diagram is disorder, and the Poincare map shows many discrete points. As $\omega_{h}$ is increased from 0.88 to 0.93 and from 1.14 to 1.19 , the system exhibits unstable period-one motion, and the period- 2 motion will be observed over the range of $1.2 \leq \omega_{h} \leq 1.29$. And as it is shown in Figure 5(c), the time domain response diagram shows a period motion, the phase plane diagram shows two closed circles, and the Poincaré map shows two unique points. Figure 5 presents time series, phase plane diagram, and Poincaré maps of Hopf bifurcation points at $\omega_{h}=0.4,0.7,1.2,1.3,1.6$, and 1.63. It can be seen that the motions of the one-way clutch, two-shaft assemblies system undergo period-1 motion, chaotic motion, period-2 motion, quasi-periodic motion, and period-7 motion.

Figure 6 presents the bifurcation diagram of the system response of dimensionless dynamic transmission error between gear 2 and the inner ring, which is essentially used to study the dynamic windup angle of one-way clutch, using excitation frequency $\omega_{h}$ as control parameter. It can be 


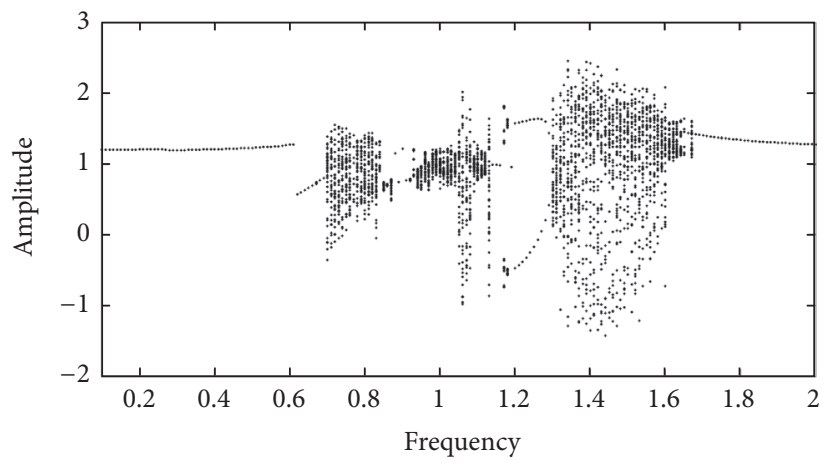

FIGURE 4: $z_{2}$ versus $\omega_{h}$, plots for $F_{a h}=0.5, F_{a T}=0, b_{h}=0, b_{1}=b_{2}=b_{c}=0.01, \widehat{k}=5, K_{c}=5 K_{c o}$, and $F_{m}=1$.

observed that the relative reverse motion between gear 2 and the inner ring exhibits rather complex phenomenon with the increase of the excitation frequency $\omega_{h}$. There exists some "frequency hopping" at $\omega_{h}=0.26,0.29$, and 0.61 , where the system undergoes the transient transition between periodone motion. Only period-one motion can be observed at low values of the excitation frequency, that is, $\omega_{h}<0.69$, or at high values of the excitation frequency, that is, $\omega_{h}>1.68$. The system performs period-2 motion within the range of $1.19 \leq \omega_{h} \leq 1.29$. The system exhibits chaotic motions within the range of $0.7 \leq \omega_{h} \leq 0.88,0.93 \leq \omega_{h} \leq 1.14$, and $1.3 \leq \omega_{h} \leq 1.68$. Unlike the transverse motion of gear 2, the relative reverse motion between gear 2 and the inner ring exhibits stable period- 1 motion within the range of $0.89 \leq \omega_{h} \leq 0.92,1.16 \leq \omega_{h} \leq 1.18$. The system goes into chaotic motions through the quasi-periodic route around excitation frequency points $\omega_{h}=0.71,0.931$, and 1.31 and goes into chaotic motions through the quasi-periodic route around excitation frequency points $\omega_{h}=0.881,1.141$, and 1.681 .

Figure 7 shows the time series, phase plane diagram, and Poincaré maps of Hopf bifurcation points at $\omega_{h}=0.4,0.7$, $1.2,1.3,1.6$, and 1.63. It can be founded that the system behavior undergoes period-1 motion, chaotic motion, period-2 motion, quasi-periodic motion, and period-7 motion with the increase of the excitation frequency $\omega_{h}$.

4.2. Effect of Torsional Stiffness of One-Way Clutch. Figure 8 presents the bifurcation diagram of the system response of dimensionless dynamic transmission error between gear 1 and gear 2, using the torsional stiffness of one-way clutch $K_{c}$ as control parameter. It can be observed from the figure that, when the torsional stiffness is changed, there exist kinds of motion forms, such as periodic-1 motion, periodic- 2 motion, periodic- 4 motion, periodic- 8 motion, and chaotic motion. In order to accurately distinguish the motion form, the time domain response diagrams, phase plane diagrams, and Poincaré maps are listed to illustrate the dynamic characteristics of the system in Figure 9. When $K_{c}$ is less than $276000 \mathrm{~N} \cdot \mathrm{m} / \mathrm{rad}$, only period-one motion can be observed. The system motion state will be changed from periodic- 1 motion to periodic- 2 motion, when the torsional stiffness of one-way clutch is increased to $276000 \mathrm{~N} \cdot \mathrm{m} / \mathrm{rad}$, and the state is continued until $331000 \mathrm{~N} \cdot \mathrm{m} / \mathrm{rad}$. The system performs the transient periodic-4 motion within the range of $331000 \mathrm{~N} \cdot \mathrm{m} / \mathrm{rad} \leq K_{c} \leq 341000 \mathrm{~N} \cdot \mathrm{m} / \mathrm{rad}$ and exhibits chaotic motions within the range of $341000 \mathrm{~N} \cdot \mathrm{m} / \mathrm{rad} \leq K_{c} \leq$ $676000 \mathrm{~N} \cdot \mathrm{m} / \mathrm{rad}$, just as shown in Figure 9(c). It can be seen that the time domain response diagram shows a nonperiodic motion, the Poincaré map shows many discrete points, and the phase plane diagram is disorder. With the increasing of the torsional stiffness, the system leaves chaos and goes into periodic-8 motion from $676000 \mathrm{~N} \cdot \mathrm{m} / \mathrm{rad}$ to $696000 \mathrm{~N} \cdot \mathrm{m} / \mathrm{rad}$. When the torsional stiffness is greater than $696000 \mathrm{~N} \cdot \mathrm{m} / \mathrm{rad}$, the system goes into another region of chaotic motion again until $811000 \mathrm{~N} \cdot \mathrm{m} / \mathrm{rad}$. After undergoing the chaotic region, the system leaves chaotic motion and goes into periodic-1 motion again within the range of $811000 \mathrm{~N} \cdot \mathrm{m} / \mathrm{rad} \leq K_{c} \leq$ $951000 \mathrm{~N} \cdot \mathrm{m} / \mathrm{rad}$. When $K_{c}$ is higher than $951000 \mathrm{~N} \cdot \mathrm{m} / \mathrm{rad}$, the system leaves periodic-1 motion and returns into chaotic motion again.

\section{Summary and Conclusions}

A general multi-degree-of-freedom nonlinear dynamic model of one-way clutch, two-shaft assembly based on lumped parameter method (LPM) is proposed in this paper. The gear backlash, bearing backlash, a nonlinear mesh stiffness $k_{h}(t)$, and mesh damping $c_{h}$ are considered in the model. The one-way clutch is modeled as a piecewise nonlinear spring with discontinuous stiffness that separates gear 2 into two degrees of freedom. The dynamic response of one-way clutch, two-shaft assemblies is studied over a wide range of frequencies. Speed sweeping is used to check the effect of one-way clutch on the nonlinear behavior of gear transmission system, by applying variable step-size Runge-Kutta method.

As mentioned above, with the increasing of excitation frequency and torsional stiffness of one-way clutch, the system of one-way clutch, two-shaft assembly is prone to involve periodic-1 motion, multiperiodic motion, and chaotic motion. Large torsional stiffness of one-way clutch can increase the impact and lead to instability in the system. To reduce the impact and increase stability, the excitation 

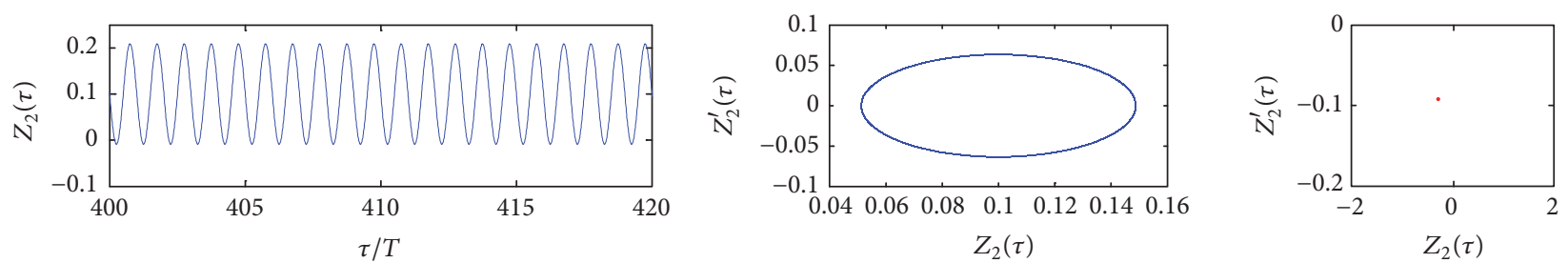

(a)
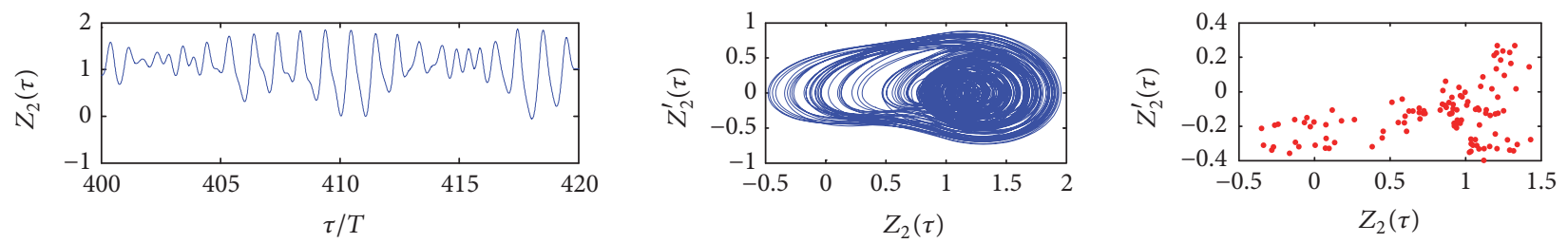

(b)
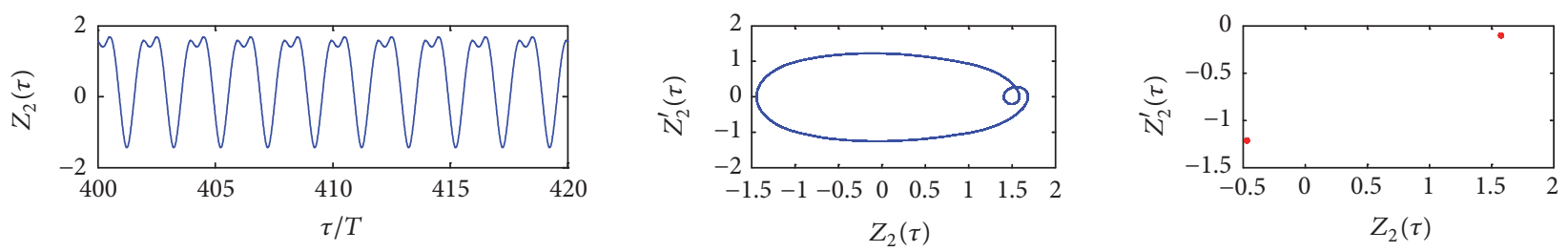

(c)
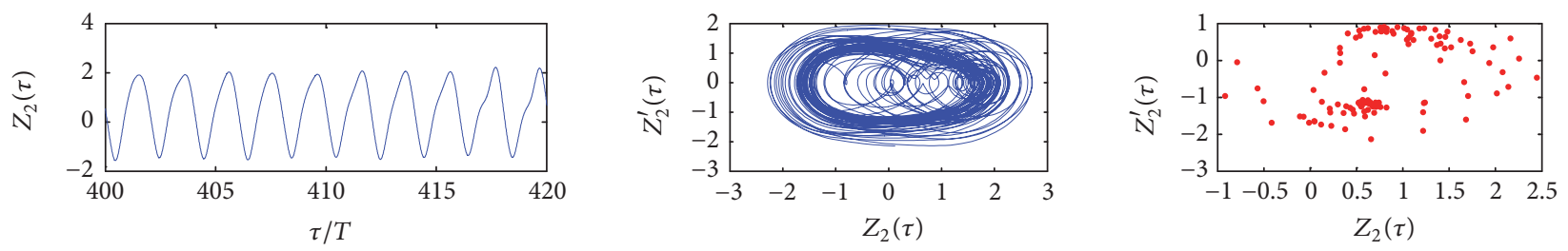

(d)
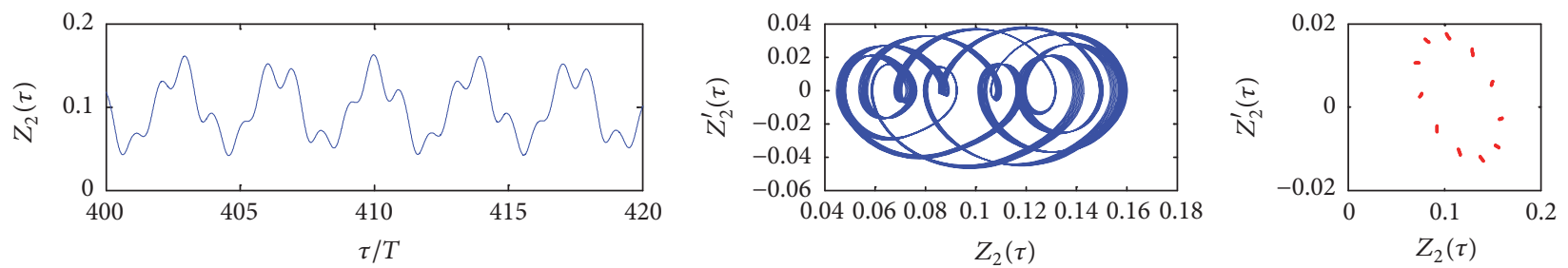

(e)
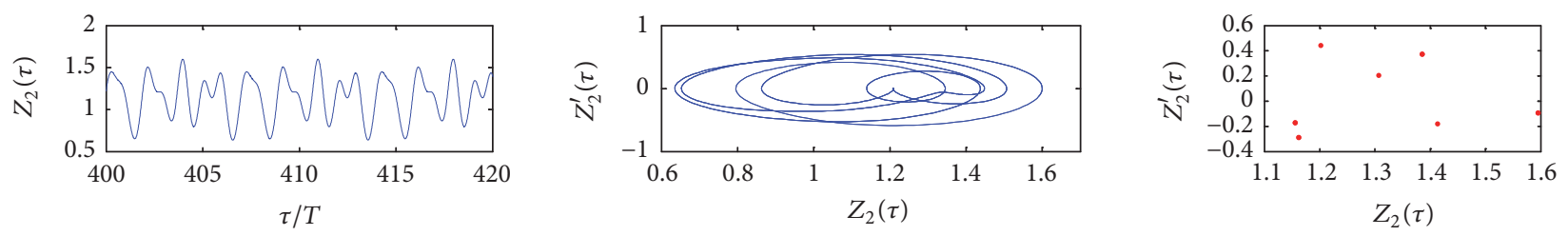

(f)

Figure 5: The time series of $z_{2}$, phase plane diagram, and Poincaré map under $F_{a h}=0.5, F_{a T}=0, b_{h}=0, b_{1}=b_{2}=b_{c}=0.01, \widehat{k}=5, K_{c}=5 K_{c o}$, and $F_{m}=1$ and different excitation frequency with them; (a) $\omega_{h}=0.4$, (b) $\omega_{h}=0.7$, (c) $\omega_{h}=1.2$, (d) $\omega_{h}=1.3$, (e) $\omega_{h}=1.6$, and (f) $\omega_{h}=1.63$. 


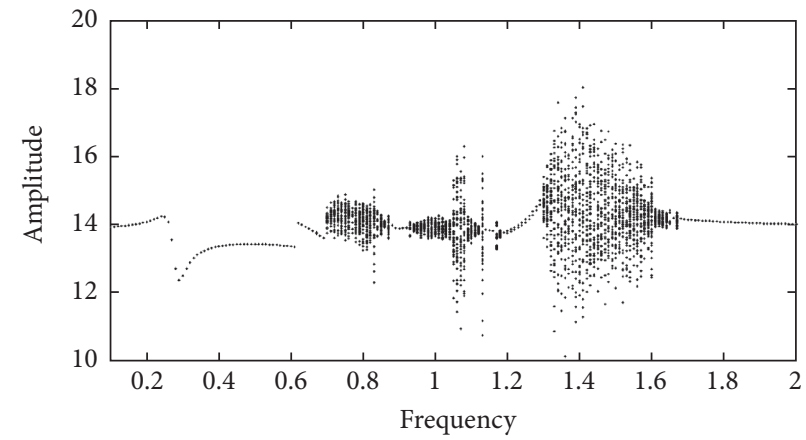

FIGURE 6: $\gamma_{2}$ versus $\omega_{h}$, plots for $F_{a h}=0.5, F_{a T}=0, b_{h}=0, b_{1}=b_{2}=b_{c}=0.01, \widehat{k}=5, K_{c}=5 K_{c o}$, and $F_{m}=1$.

frequency of the engine and the torsional stiffness of the oneway clutch are taken into account to be based on matching and optimization principles for the system of one-way clutch, two-shaft assembly.

\section{Nomenclature}

\footnotetext{
$r_{1}: \quad$ Base circle radius of gear 1

$r_{2}: \quad$ Base circle radius of gear 2

$I_{1}$ : Mass moment of inertia of gear 1

$I_{2}$ : Mass moment of inertia of gear 2

$I_{o}$ : $\quad$ Mass moment of inertia of inner ring

$m_{1}$ : Mass representing inertia of gear 1

$m_{2}$ : Mass representing inertia of gear 2

$m_{o}$ : Mass representing inertia of inner ring

$m_{c}$ : Equivalent gear pair mass

$c_{1}$ : Viscous damping coefficient of bearing 1

$c_{2}$ : Viscous damping coefficient of bearing 2

$c_{h}$ : Viscous damping coefficient of gear pair

$C_{c}$ : Torsional damping of one-way clutch

$k_{1}$ : Contact stiffness of bearing 1

$k_{2}$ : Contact stiffness of bearing 2

$k_{h}$ : Time-varying mesh stiffness of gear pair

$K_{c}$ : Torsional stiffness of one-way clutch

$f_{1}$ : Force-displacement function of bearing 1

$f_{2}$ : $\quad$ Force-displacement of bearing 2

$f_{h}$ : Nonlinear displacement function of gear pair

$F_{1}$ : Preload applied on bearing 1

$F_{2}$ : Preload applied on bearing 2

$F_{o}$ : Force transmitted through one-way clutch

$T_{1}$ : Torque acting on gear 1

$T_{2}$ : Torque acting on gear 2

$T_{o}$ : Torque acting on inner ring

$T_{1 m}$ : Average torque acting on gear 1

$T_{1 a T}$ : Fluctuating torque acting on gear 1

$y_{1}$ : Transverse displacement of gear 1

$y_{2}$ : Transverse displacement of gear 2

$y_{g 1}$ : Displacement on direction of mesh line of gear 1
}

$y_{g 2}:$ Displacement on direction of mesh line of gear 2

$y_{c o}$ : Displacement on direction of mesh line of inner ring

$\theta_{1}$ : Torsional displacement of gear 1

$\theta_{2}$ : Torsional displacement of gear 2

$\theta_{o}$ : Torsional displacement of inner ring

$e$ : Static transmission error

$b_{1}$ : The half of backlash of bearing 1

$b_{2}$ : The half of backlash of bearing 2

$b_{h}$ : The half of backlash of the gear pair

$b_{c}$ : The characteristic length

$\omega_{e}$ : Excitation frequency of static transmission error

$\omega_{a}$ : Excitation frequencies of external torque

$\omega_{n}$ : Natural frequency $\omega_{n}=\sqrt{k_{h} / m_{c}}$

$\varepsilon_{r}$ : Involute contact ratio

$z_{1}$ : Dimensionless transverse displacement of gear 1

$z_{2}$ : Dimensionless transverse displacement of gear 2

$\gamma_{1}$ : The dimensionless difference between the dynamic transmission error $\left(y_{g 1}-y_{g 2}+y_{1}-y_{2}\right) / b_{c}$ and the static transmission of the gear pair $\left(y_{g 1}-y_{g 2}+y_{1}-y_{2}-e\right) / b_{c}$

$\gamma_{2}$ : The dimensionless difference of the displacement on direction of mesh line of gear 2 and the displacement on direction of mesh line of inner ring of one-way clutch

q: The difference between the dynamic transmission error $\left(y_{g 1}-y_{g 2}+y_{1}-y_{2}\right)$ and the static transmission $(e)$ of the gear pair $\left(y_{g 1}-y_{g 2}+y_{1}-y_{2}-e\right)$

$q_{o}$ : The difference of the displacement on direction of mesh line of gear 2 and the displacement on direction of mesh line of inner ring of one-way clutch. 

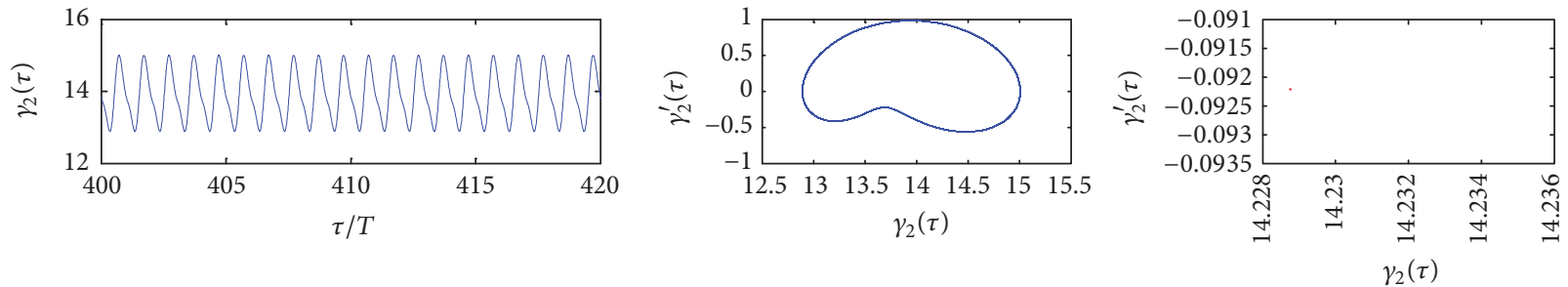

(a)
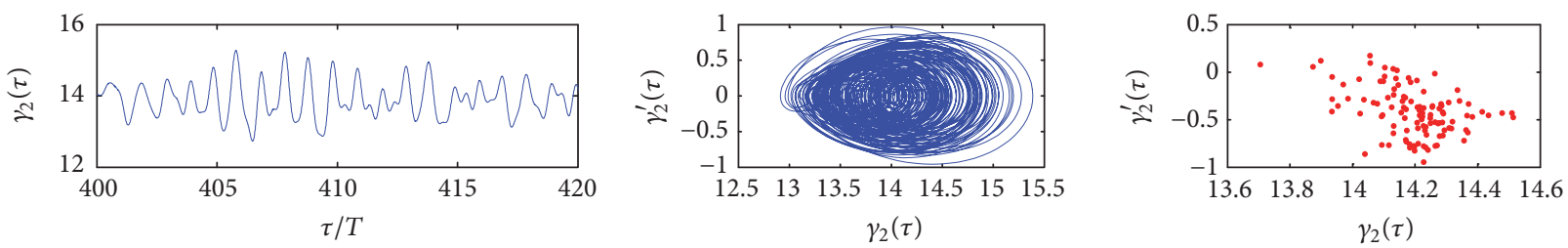

(b)
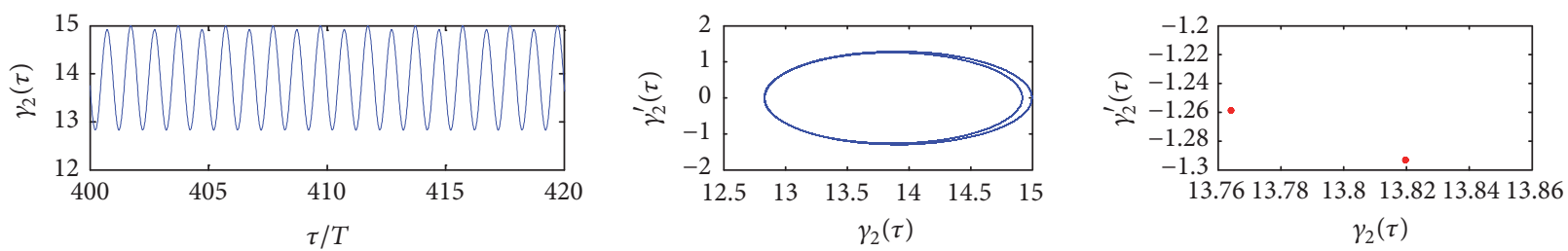

(c)
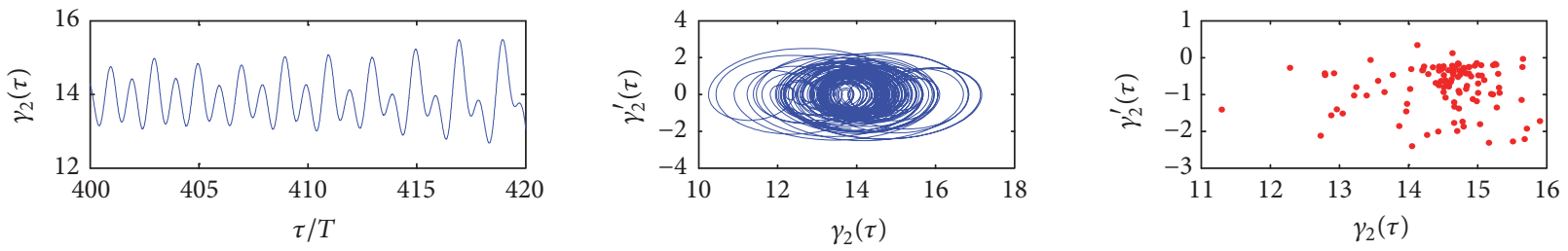

(d)
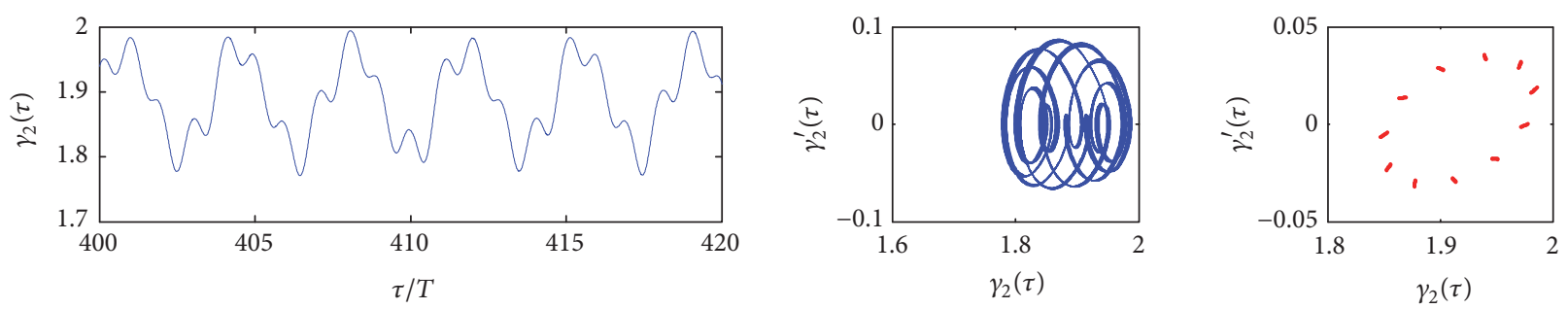

(e)
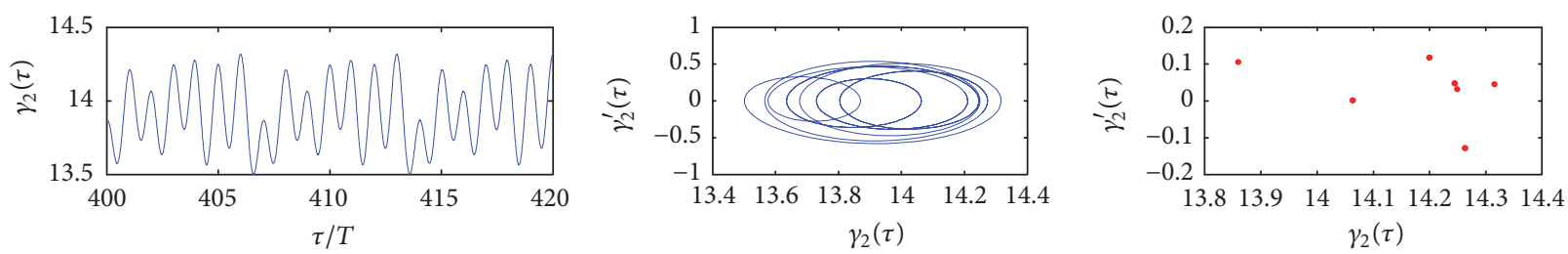

(f)

Figure 7: The time series of $\gamma_{2}$, phase plane diagram, and Poincaré map under $F_{a h}=0.5, F_{a T}=0, b_{h}=0, b_{1}=b_{2}=b_{c}=0.01, \widehat{k}=5, K_{c}=5 K_{c o}$, and $F_{m}=1$ and different excitation frequency with them; (a) $\omega_{h}=0.4$, (b) $\omega_{h}=0.7$, (c) $\omega_{h}=1.2$, (d) $\omega_{h}=1.3$, (e) $\omega_{h}=1.6$, and (f) $\omega_{h}=1.63$. 


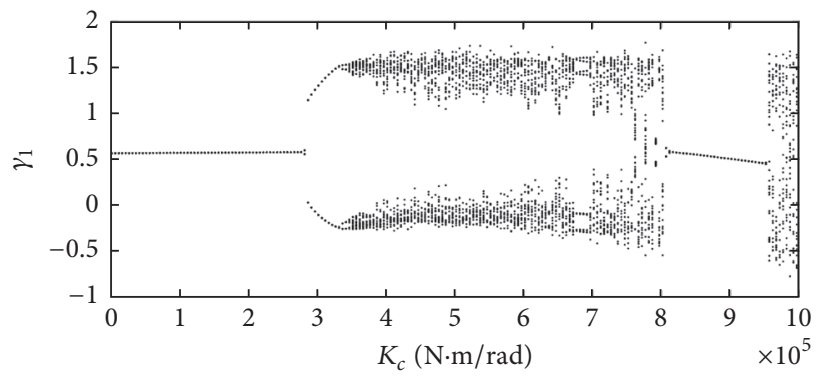

FIGURE 8: $\gamma_{1}$ versus $K_{c}$, plots for $F_{a h}=0.5, F_{a T}=0, b_{h}=0, b_{1}=b_{2}=b_{c}=0.01, \widehat{k}=5, \omega_{h}=1.25$, and $F_{m}=1$.
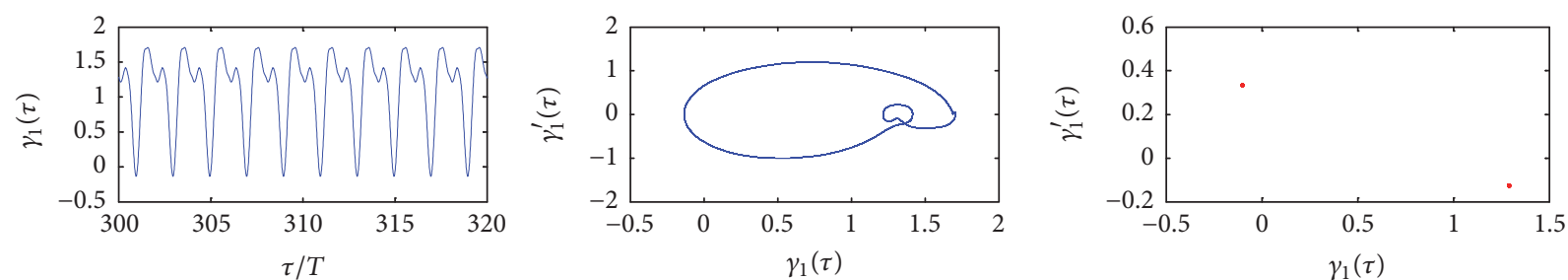

(a)
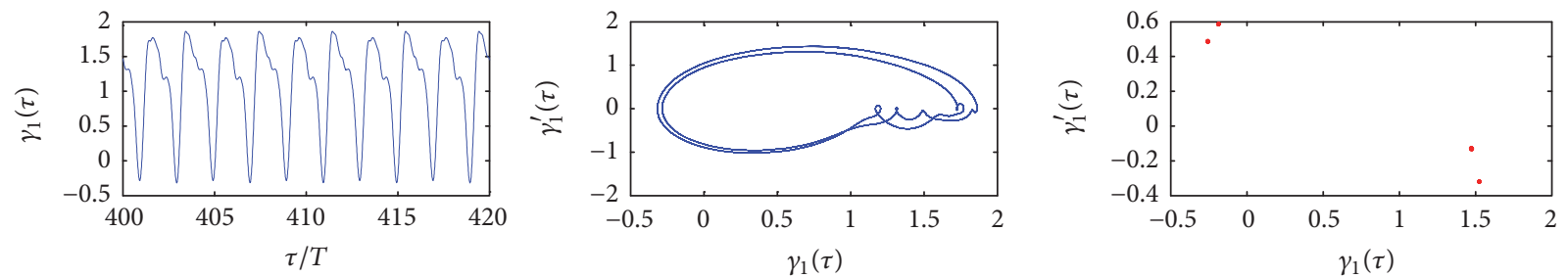

(b)
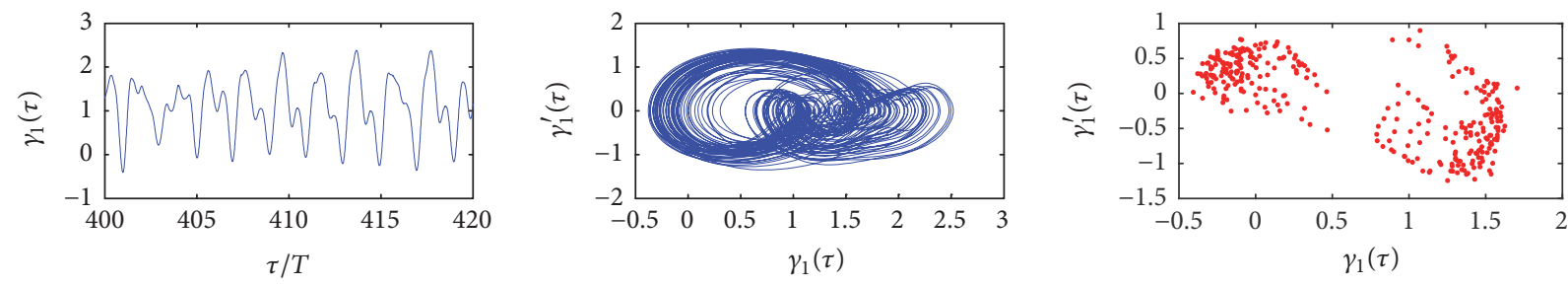

(c)
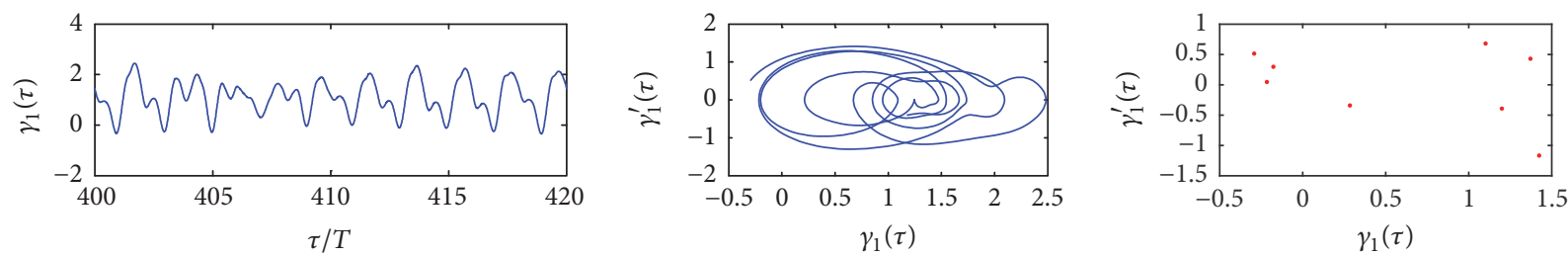

(d)

Figure 9: The time series of $\gamma_{1}$, phase plane diagram, and Poincaré map under $F_{a h}=0.5, F_{a T}=0, b_{h}=0, b_{1}=b_{2}=b_{c}=0.01, \widehat{k}=5$, $\omega_{h}=1.25$, and $F_{m}=1$ and different torsional stiffness of one-way clutch with them; (a) $K_{c}=300000 \mathrm{~N} \cdot \mathrm{m} / \mathrm{rad},(\mathrm{b}) K_{c}=341000 \mathrm{~N} \cdot \mathrm{m} / \mathrm{rad},(\mathrm{c})$ $K_{c}=600000 \mathrm{~N} \cdot \mathrm{m} / \mathrm{rad}$, and $(\mathrm{d}) K_{c}=688000 \mathrm{~N} \cdot \mathrm{m} / \mathrm{rad}$.

\section{Conflicts of Interest}

The authors declare that there are no conflicts of interest regarding the publication of this paper.

\section{Acknowledgments}

The authors thank the Key Research and Development Program in Hunan Province (no. 2015JC3007), the Basic 
Research on Digital Machining of Hard Processed Aeronautical Parts (no. 2011CB706800), and General Project in Hunan Province Department of Education (no. 15c1239) for financial support.

\section{References}

[1] S. Chen, J. Tang, C. Luo, and Q. Wang, "Nonlinear dynamic characteristics of geared rotor bearing systems with dynamic backlash and friction," Mechanism and Machine Theory, vol. 46, no. 4, pp. 466-478, 2011.

[2] I. Atanasovska, "The mathematical phenomenological mapping in non-linear dynamics of spur gear pair and radial ball bearing due to the variable stiffness," International Journal of Non-Linear Mechanics, vol. 73, pp. 114-120, 2015.

[3] A. Fernandez Del Rincon, F. Viadero, M. Iglesias, P. García, A. De-Juan, and R. Sancibrian, "A model for the study of meshing stiffness in spur gear transmissions," Mechanism and Machine Theory, vol. 61, pp. 30-58, 2013.

[4] S. He, R. Gunda, and R. Singh, "Effect of sliding friction on the dynamics of spur gear pair with realistic time-varying stiffness," Journal of Sound and Vibration, vol. 301, no. 3-5, pp. 927-949, 2007.

[5] M. A. Hotait and A. Kahraman, "Experiments on the relationship between the dynamic transmission error and the dynamic stress factor of spur gear pairs," Mechanism and Machine Theory, vol. 70, pp. 116-128, 2013.

[6] Z. Liu, Z. Liu, J. Zhao, and G. Zhang, "Study on interactions between tooth backlash and journal bearing clearance nonlinearity in spur gear pair system," Mechanism and Machine Theory, vol. 107, pp. 229-245, 2017.

[7] Q. Ma and A. Kahraman, "Period-one motions of a mechanical oscillator with periodically time-varying, piecewise-nonlinear stiffness," Journal of Sound and Vibration, vol. 284, no. 3-5, pp. 893-914, 2005.

[8] L. Walha, T. Fakhfakh, and M. Haddar, "Nonlinear dynamics of a two-stage gear system with mesh stiffness fluctuation, bearing flexibility and backlash," Mechanism and Machine Theory, vol. 44, no. 5, pp. 1058-1069, 2009.

[9] R. G. Parker, S. M. Vijayakar, and T. Imajo, "Non-linear dynamic response of a spur gear pair: modelling and experimental comparisons," Journal of Sound and Vibration, vol. 237, no. 3, pp. 435-455, 2000.

[10] A. Al-Shyyab and A. Kahraman, "Non-linear dynamic analysis of a multi-mesh gear train using multi-term harmonic balance method: sub-harmonic motions," Journal of Sound and Vibration, vol. 279, no. 1-2, pp. 417-451, 2005.

[11] A. Farshidianfar and A. Saghafi, "Bifurcation and chaos prediction in nonlinear gear systems," Shock and Vibration, vol. 2014, Article ID 809739, 8 pages, 2014.

[12] J. Wang, G. He, J. Zhang, Y. Zhao, and Y. Yao, "Nonlinear dynamics analysis of the spur gear system for railway locomotive," Mechanical Systems and Signal Processing, vol. 85, pp. 4155, 2017.

[13] L. Xiang, Y. Jia, and A. Hu, "Bifurcation and chaos analysis for multi-freedom gear-bearing system with time-varying stiffness," Applied Mathematical Modelling. Simulation and Computation for Engineering and Environmental Systems, vol. 40, no. 23-24, pp. 10506-10520, 2016.
[14] C.-W. Chang-Jian and S.-M. Chang, "Bifurcation and chaos analysis of spur gear pair with and without nonlinear suspension," Nonlinear Analysis. Real World Applications. An International Multidisciplinary Journal, vol. 12, no. 2, pp. 979-989, 2011.

[15] X.-F. Gou, L.-Y. Zhu, and D.-L. Chen, "Bifurcation and chaos analysis of spur gear pair in two-parameter plane," Nonlinear Dynamics, vol. 79, no. 3, pp. 2225-2235, 2014.

[16] M. T. Khabou, N. Bouchaala, F. Chaari, T. Fakhfakh, and M. Haddar, "Study of a spur gear dynamic behavior in transient regime," Mechanical Systems and Signal Processing, vol. 25, no. 8, pp. 3089-3101, 2011.

[17] P. Vernay, G. Ferraris, A. Delbez, and P. Ouplomb, “Transient behaviour of a sprag-type over-running clutch: an experimental study," Journal of Sound and Vibration, vol. 248, no. 3, pp. 567572, 2001.

[18] C. Gill-Jeong, "Nonlinear behavior analysis of spur gear pairs with a one-way clutch," Journal of Sound and Vibration, vol. 301, no. 3-5, pp. 760-776, 2007.

[19] E. M. Mockensturm and R. Balaji, "Piece-wise linear dynamic systems with one-way clutches," Transactions of the ASME, Journal of Vibration and Acoustics, vol. 127, no. 5, pp. 475-482, 2005.

[20] F. Zhu and R. G. Parker, "Non-linear dynamics of a one-way clutch in belt-pulley systems," Journal of Sound and Vibration, vol. 279, no. 1-2, pp. 285-308, 2005.

[21] F. Zhu and R. G. Parker, "Perturbation analysis of a clearancetype nonlinear system," Journal of Sound and Vibration, vol. 292, no. 3-5, pp. 969-979, 2006.

[22] H. Ding and J. W. Zu, "Effect of one-way clutch on the nonlinear vibration of belt-drive systems with a continuous belt model," Journal of Sound and Vibration, vol. 332, no. 24, pp. 6472-6487, 2013.

[23] H. Ding, "Periodic responses of a pulley-belt system with oneway clutch under inertia excitation," Journal of Sound and Vibration, vol. 353, pp. 308-326, 2015.

[24] H. Ding and D.-P. Li, "Static and dynamic behaviors of beltdrive dynamic systems with a one-way clutch," Nonlinear Dynamics. An International Journal of Nonlinear Dynamics and Chaos in Engineering Systems, vol. 78, no. 2, pp. 1553-1575, 2014.

[25] H. Ding and J. W. Zu, "Steady-state responses of pulley-belt systems with a one-way clutch and belt bending stiffness," Journal of Vibration and Acoustics, Transactions of the ASME, vol. 136, no. 4, Article ID 041006, 2014.

[26] T. Xu and G. G. Lowen, "A mathematical model of an overrunning sprag clutch," Mechanism and Machine Theory, vol. 29, no. 1, pp. 11-23, 1994. 


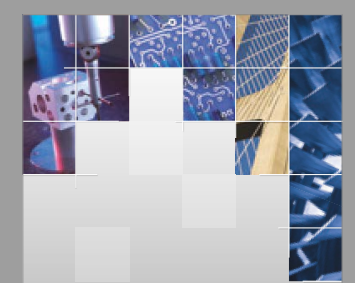

\section{Enfincering}
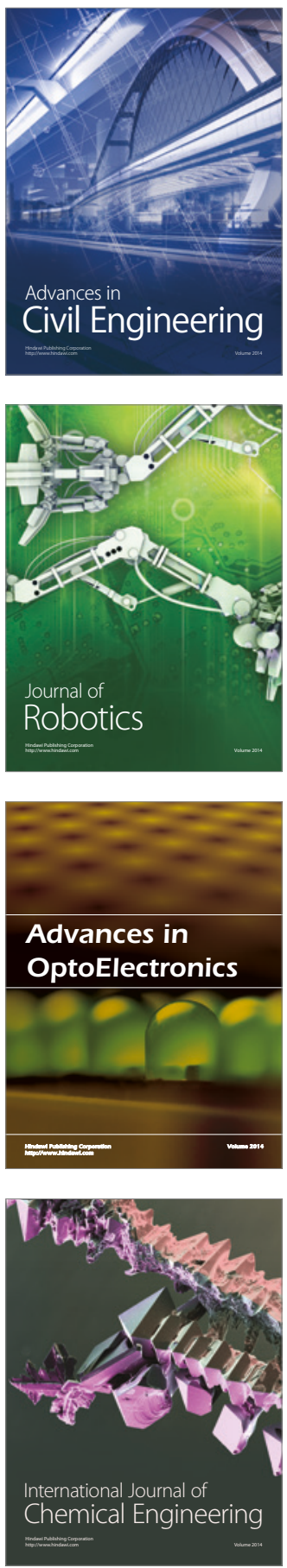

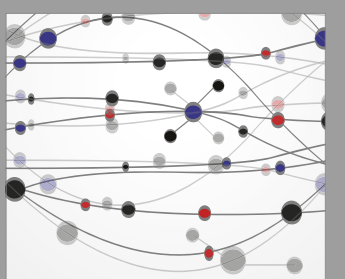

The Scientific World Journal

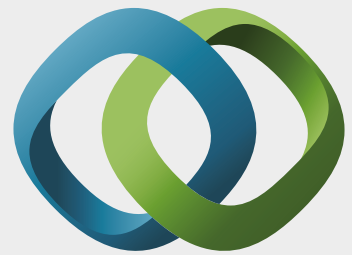

\section{Hindawi}

Submit your manuscripts at

https://www.hindawi.com
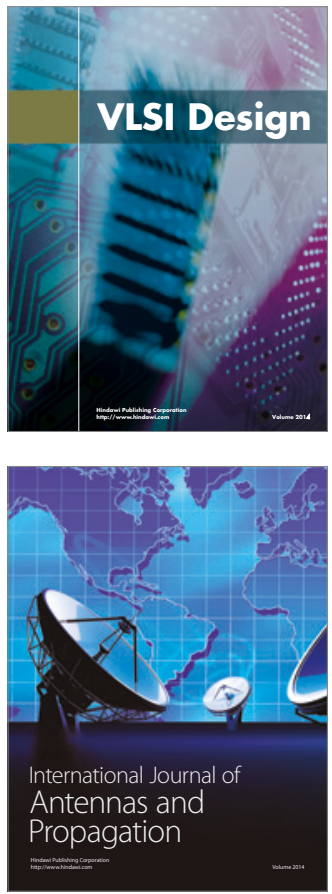

\section{Rotating}

Machinery
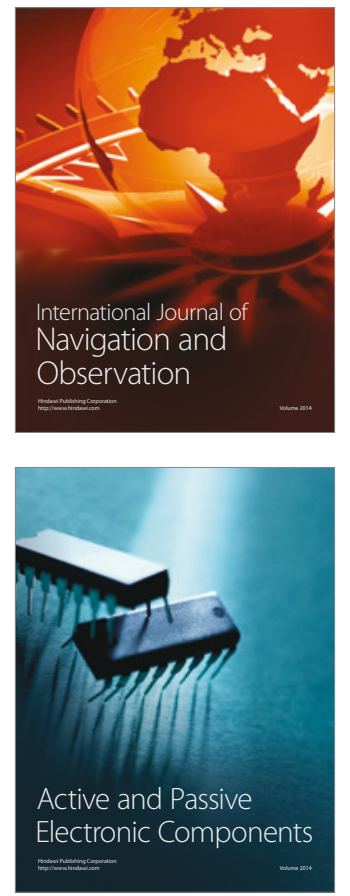
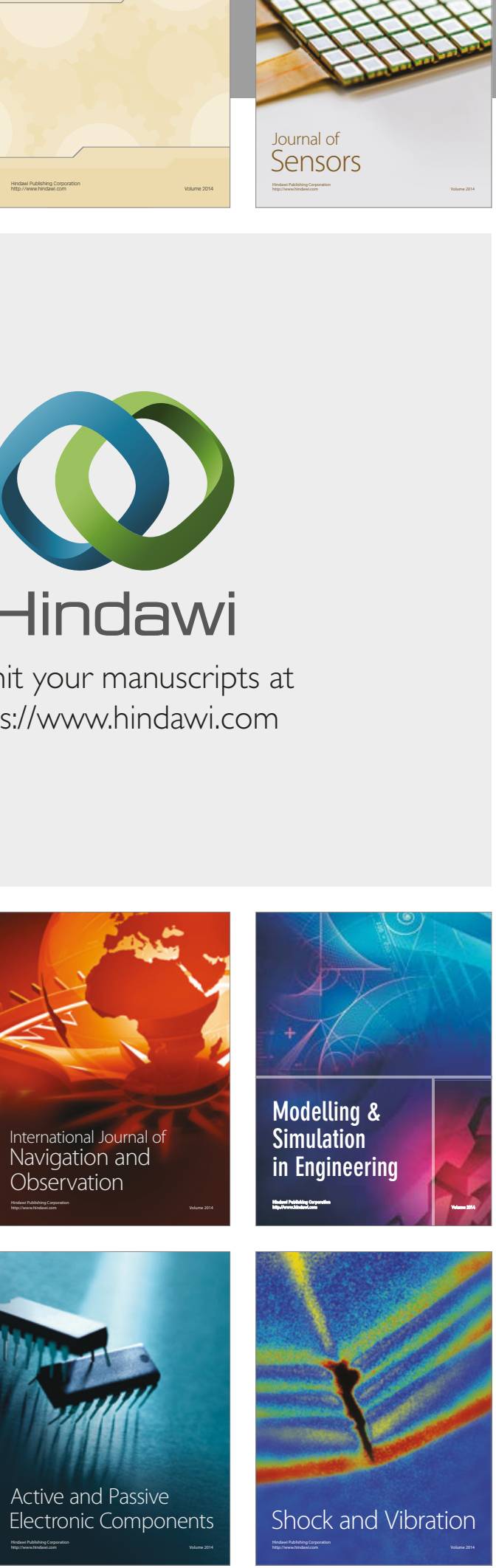
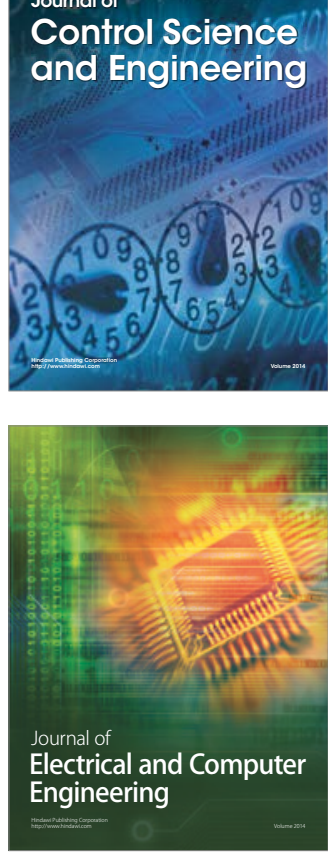

Distributed

Journal of

Control Science

and Engineering
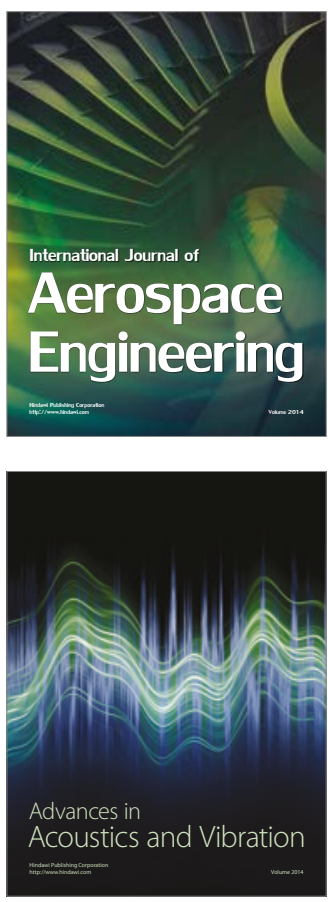

Sensor Networks 